\title{
Çocukluk çağı keratokonus hastalarında çapraz bağlama tedavisi: Uzun dönem sonuçlarımız
}

\author{
Serkan Kılınç¹, Burcu Kasım², Yusuf Koçluk ${ }^{3}$ \\ ${ }^{1}$ Tarsus Devlet Hastanesi, Göz Hastalıkları Kliniği, Mersin \\ ${ }^{2}$ Adana Şehir Eğitim ve Araştırma Hastanesi, Göz Hastalıkları Kliniği, Adana \\ ${ }^{3}$ Adana Şehir Eğitim ve Araştırma Hastanesi, Göz Hastalıkları Kliniği, Adana
}

\section{$\ddot{0} \mathbf{z}$}

Amaç: Keratokonus nedeniyle kollajen çapraz bağlama (KÇB) tedavisi uygulanmış çocuk hastalarda, uzun dönem topografik analiz sonuçlarının değerlendirilmesi. Yöntem: Temmuz 2015 ile temmuz 2017 tarihleri arasında Adana Numune Eğitim ve Araştırma Hastanesi Göz Hastalıkları Kornea biriminde 18 yaş altı, keratokonus tanısıyla hızlandırılmıș KÇB tedavisi uygulanan 35 hastanın 53 gözü retrospektif olarak değerlendirildi. Tedavi öncesi ve takip sonu, Pentacam ile elde edilen merkezi ve en ince kornea kalınlığı, ön ve arka yüzey keratometrik değerleri, korneal dansitometri, Belin/Ambrósio D indeksi karşılaştırıldı. Bulgular: Takip sonunda kornea ön yüzey keratometri ve en yüksek keratometri değerlerinde KÇB öncesine göre istatistiksel olarak anlamlı azalma saptanmıştır (sırası ile, $\mathrm{p}=0.031, \mathrm{p}=0.029$ ). Merkezi kornea kalınlığı ve en ince kornea kalınlığı takip sonunda KÇB öncesine göre istatiksel olarak anlamlı düşük bulundu (sırası ile $\mathrm{p}=0.005, \mathrm{p}<0.001$ ) Ön yüzey asferisite, istatistiksel olarak değişmezken, korneal dansitometri ve topografik astigmatizmada anlamlı artış izlendi (sırası ile, $\mathrm{p}<0.001, \mathrm{p}=0.031$ ). Allerjik konjonktivit bulunan olgularla, bulunmayan olgular karşılaştırıldığında, korneal dansitometri ve kornea kalınlığı değişikliklerinde anlamlı fark saptanmadı (sırası ile, p=0.728, p=0.513). Sonuç: Pediyatrik keratokonusta, hızlandırılmış KÇB tedavisi, etkili ve güvenilir bir yöntemdir.

Anahtar sözcükler: Keratokonus, kollajen çapraz bağlama, topografi

\section{Results of corneal crosslinking in pediatric keratoconus: Long-term results}

\begin{abstract}
Aim: To evaluate the long-term outcomes of collagen cross-linking (CXL) in pediatric keratoconus. Method: 53 eyes of 35 patients with keratoconus under the age of 18 and underwent accelerated collagen crosslinking treatment in Adana Numune Training and Research Hospital between July 2015 and July 2018 were evaluated retrospectively. Preoperative and postoperative topographic parameters, obtained by using Pentacam, such as, central and thinnest corneal thickness, keratometric parametres of anterior and posterior surfaces, corneal dansitometry values and D index of Belin/Ambrósio were compared.
\end{abstract}

Yazının geliş tarihi:26.09.2018

Yazının kabul tarihi:07.11.2018

Sorumlu Yazar: Uzm.Dr. Serkan Kılınç, Göz Hastalıkları Uzmanı; Tarsus Devlet Hastanesi, Göz Hastalıkları Kliniği, Mersin,Tel:05065594409

E-posta: drserkan333455@gmail.com 
Results: At the end of the follow-up, corneal anterior surface keratometer and maximum keratometry values were found to be decreased statistically significant when compared to preoperative values $(\mathrm{p}=0.031, \mathrm{p}=0.029$, respectively) Central corneal thickness and corneal thikness at the thinnest point were also decreased significantly at the end of follow-up ( $p=0.005$, $\mathrm{p}<0.001$, respectively). There was no statistically significant difference in the anterior corneal asphericity. However, corneal densitometry and topographic astigmatism were found to be increased, significantly $(\mathrm{p}<0.001, \mathrm{p}=0.031$, respectively). No statistically significant difference was found in corneal densitometry or in corneal thickness, when compared between the patients with and without allergic conjunctivitis $(\mathrm{p}=0.728, \mathrm{p}=0.513$, respectively). Conclusion: Accelerated CXL treatment is an effective and reliable method in pediatric keratoconus

Keywords: Keratoconus, collagen cross-linking, topography

\section{Giriş}

Keratokonus (KK), korneanin genellikle bilateral ve asimetrik seyreden non-inflamatuar progresif ektazisidir. Korneada progresif ektazi ve incelme, düzensiz astigmatizmaya ve görme keskinliğinde kayıplara yol açar. ${ }^{1} \mathrm{KK}$, genellikle ergenlik döneminde başlar, kademeli, hızlı veya aralıklı değişken olarak progresyon gösterir. Progresyon, kırklı yaşlarda yavaşlamaktadır. ${ }^{2}$ Çocuklarda ise sıklıkla daha ileri evrelerde tanı konur ve progresyon, erişkinlere göre daha hızlıdır.3,4 Keratoplasti prognozu oldukça iyi olmakla beraber, gelişebilecek intraoperatif komplikasyonlar ve olası greft red reaksiyonları nedeniyle, özellikle ileri evrelerde tercih edilmektedir. ${ }^{5} \mathrm{Bu}$ nedenle, kornea transplantasyon ihtiyacını azaltmak için erken yaşlarda hastalığın ilerlemesini durdurmak gerekliliği ortaya çıkmıştır.

Günümüzde, progresyonun durdurulması ve keratoplastiye olan ihtiyacın azaltılmasında güvenilir tek tedavi yöntemi kornea kollajen

çapraz bağlama (KÇB) tedavisidir ve yaygın olarak kullanılmaktadır.6-9 $\mathrm{Bu}$ tedavi, fotosensitize edici riboflavin ve Ultraviyole A (UVA) ışınları sayesinde kollajen fibrilleri arasındaki kovalent bağları arttırır ve kollajen matriks biyomekaniğini güçlendirerek keratokonusun ilerlemesini durdurur. 10,11 Çocuklarda, KÇB ile ilgili yapılan çalışmalar, yetişkinlere göre sınırlı olmasına rağmen, KÇB'in keratokonus ilerlemesinin önlenmesi için güvenli ve etkili bir yöntem olduğu ortaya konmuştur.12-14
$\mathrm{Bu}$ çalıșmanın amacı, KK tanısıyla KÇB tedavisi uygulanmış pediatrik hastalarda, KÇB tedavisinin uzun dönem topografik analiz sonuçlarının değerlendirilmesidir.

\section{Gereç ve yöntem}

$\mathrm{Bu}$ klinik, retrospektif çalışmada, Temmuz 2015 ile Temmuz 2018 tarihleri arasında Adana Numune Eğitim ve Araştırma Hastanesi Göz Hastalıkları Kornea Biriminde en az 12 aylık takibi bulunan, 18 yaş ve altı, herhangi bir sistemik hastalığı olmayan, korneası saydam, KK tanısı alan ve hızlandırılmış KÇB yapılmış, 35 çocuk hastanın 53 gözüne ait kayıtlar incelendi. Çalışma, Adana Şehir Eğitim ve Araștırma Hastanesi klinik araştırmalar etik kurulu tarafından 15.08.2018 tarih ve 255 numaralı karar ile onaylandı ve çalışma süresince Helsinki Bildirisi kurallarına uyuldu.

Topografik olarak KK teşhisi kesin olan olgulara ilk muayeneleri sonrasinda KÇB tedavisi önerilmişti. Kesin KK tanısında maksimum keratometri değerinin (Kmax) 47.2'nin üzerinde olması, en ince kornea kalınlığının $470 \mu$ m'nin altında olması, $\mathrm{K}$ değeri farkının alt ve üst yarı arasında 1.5D'den fazla olması, elevasyon haritalarında en iyi oturtulmuş küre (best fit sphere [BFS]) değerinin ön yüzeyde 8 , arka yüzeyde 18 'in üzerinde olması kriter olarak belirlendi. $\mathrm{Bu}$ kriterlerden hepsini sağlamayan, kalınlık haritasında tipik KK görüntüsü olmayan olgular şüpheli olarak değerlendirildi. 6 ay içerisinde Kmax değerinin 1D'den fazla artması ve/veya merkezi korneal kalınlığın $30 \mu \mathrm{m}$ 'den fazla 
azalması ve/veya topografik astigmatizma değerinin 1D'den fazla artması progresif keratokonus olarak değerlendirilmiş ve KÇB kararı verilmişti. Bunun yanında, şüpheli durumlarda 6 aylık takipler ile değerlendirmeler sonucunda topografik ilerleme gözlenilmesi durumunda işlem gerçekleştirilmişti. Hastaların KÇB öncesi ve postoperatif periodik takiplerde en iyi düzeltilmiş görme keskinliği ve Scheimpflug görüntüleme içeren Pentacam cihazı (Oculus Optik gerate, Wetzlar, Almanya) topografi haritalarından elde edilen; apikal dansitometri, Kmöy (kornea ön yüzey keratometri), topografik astigmatizma (TA), Q (Ön yüzey asiferisite ), merkezi kornea kalınlığ $(\mathrm{MKK})$, en ince noktada kornea kalınlığ (KK en ince nokta), maksimum keratometri değeri (Kmax), ortalama progresyon indeksi, ortalama Belin / AmbrósioD indeksi (B/A) değerlerini içeren dosya verileri değerlendirilmiștir.

Allerjik konjonktivitin korneal dansitometri ve kalınlık üzerine etkisinin değerlendirilmesi amacıyla hastalar alerjik konjonktivit öyküsü olan ( $n=20$ göz) ve olmayan olarak iki gruba ayrıldı ( $n=33$ göz). Allerjik konjonktivit öyküsü olan tüm olgulara eğer kullanmiyorlarsa uzun süreli siklosporin A damla ve suni gözyaşı ve takip süresince alevlenme dönemlerinde kısa süreli ketotifen ve loteprednol damla tedavisi başlanmıştı.

Hastalar işlem öncesi, işlem sonrası 1.gün, 1.hafta, 1.ay ve sonrasında 6 aylık takip kayıtları incelendi. Son kontrol muayeneleri eksik olan olgular aranarak topografik ölçümleri tamamlandı. Kayıtları ve takipleri eksik, topografi çekim kalitesi yetersiz olgular çalışma dışı bırakıldı.

\section{KÇB prosedürü}

Korneal KÇB, steril şartlarda ve topikal anestezi (Alcaine \% 0.5; Alcon) altında uygulandı. Künt bir bıçak kullanılarak, $8.00 \mathrm{~mm}$ 'lik kornea santral alandaki epitel kaldırıldı. 30 dakika boyunca 3 dakikada bir \% 0.1riboflavin solüsyonu (Merriboiso-osmalar, Meran Medical, İstanbul, Türkiye) kornea yüzeyine uygulandı. İnce kornealarda (en ince noktada 370-420 $\mu \mathrm{m}$ ), hipo-osmalar \% 0.1riboflavin (Merribohipo-osmalar, Meran
Medical, İstanbul, Türkiye) tercih edildi. $\mathrm{Bu}$ olgularda riboflavin uygulamasından sonra ultrasonik pakimetre ile kornea kalınlığının $400 \mu \mathrm{m}$ 'nin üzerinde olduğu kontrol edildi, değil ise distile su ile yeterli kornea kalınlığına ulaşılması sağlandı. Daha sonra, 10 dakika boyunca $370 \mathrm{~nm}$ dalga boyunda UVA ( $9 \mathrm{~mW} / \mathrm{cm}^{2}$ ) (Apollon Çapraz Bağlama Sistemi, İstanbul, Türkiye) kornea yüzeyinden $5 \mathrm{~cm}$ uzaklıktan epiteli mekanik olarak kazınmış $8 \mathrm{~mm}$ 'lik alana uygulandı. Kornea, UVA uygulaması boyunca, her 2 dakikada bir riboflavin solüsyonuyla yıkandı. UVA işlemi sırasında oda aydınlatılması kapatıldı. Kornea, ișlem sonrası steril salin ile yıkandı ve teröpatik kontakt lens (TKL) uyguland.

Postoperatif dönemde, hastalara 2 hafta boyunca günde 4 kez $0.05 \%$ moksifloksasin hidroklorid göz damlası, 1 ay boyunca günde $4 \mathrm{kez} 5 \%$ florometolon göz damlası, 3 ay boyunca prezervan içermeyen suni gözyaşı damlası kullanıldı. Ameliyat sonrası 1.hafta kontrolünde TKL uzaklaştırıldı ve epitelizasyon kontrol edildi. Tüm kontroller topografik değerlendirmeler ile yapıldı. Aynı zamanda, hastalarda oküler alerji varlığının, işlem sonrası topografik dansitometri ve kornea kalınlık değerlerine etkisinin olup olmadığ araştırıldı.

\section{Istatistiksel analiz}

İstatistiksel analizler SPSS for Windows 16,0programı (SPSS Inc. Chicago, ABD) ile yapıldı. Verilerin normal dağılıp dağılmadığı kontrol edildi. Homojenite testleri yapıldı. Niceliksel değişkenler ortalama \pm standart sapma olarak ve niteliksel değișkenler ise yüzdelik oran şeklinde sunuldu. Ameliyat öncesine göre sonrasında oluşan sayısal farklılıklar eşleştirilmiş örneklem T testi ile değerlendirildi. Allerjinin gruplardaki etkisi ilişkili örneklem iki yönlü varyans analizi ile karșılaștırıldı. P değerinin 0.05 'ten küçük olması istatistiksel olarak anlamlı kabul edildi.

\section{Bulgular}

Toplam 35 hastanın 53 gözüne KÇB uygulandı. Ortalama takip süresi $21.20 \pm 9.35$ aydı (12-36 ay) . Hastaların yaş ortalaması $14.69 \pm 2.71$ (10-18 yaş) yıldı. Hastaların 16 
(\%45.71)'ü erkek, 19 (\% 54.29)'sı kadındı. 13 hastada (20 göz) alerjik konjonktivit nedeniyle aralıklı antiallerjik tedavi ve allerji öyküsü mevcuttu.

Hastalarda, intraoperatif ve postoperatif dönemde herhangi bir komplikasyonla karşılaşılmadı. Ortalama 21.2 aylık bir takip süresi sonunda hiçbir olguda progresyon nedeniyle ikinci bir tedaviye ihtiyaç duyulmadı. İşlem öncesi ve en son muayenedeki elde edilen bazı topografik değerler Tablo 1'de sunulmuştur.

Allerjik konjonktiviti olan ve olmayan olgular karşılaştırıldığında, dansitometri değerleri ve kornea kalınlığında gruplar arasında istatistiksel olarak anlamlı bir fark bulanmadı (Tablo 2)

Tablo 1. Olguların uygulama öncesi ve sonrası topografi verileri

\begin{tabular}{|c|c|c|c|}
\hline (En l & $\begin{array}{l}\text { KÇB öncesi } \\
\text { ortalama } \pm \text { sd } \\
\text { xüçük-En yüksek) }\end{array}$ & $\begin{array}{c}\text { Takip sonu } \\
\text { ortalama } \pm \text { sd } \\
\text { (En küçük-En yüksek) }\end{array}$ & $\mathrm{p}$ \\
\hline Astigmatizma (D) & $\begin{array}{c}4.46 \pm 2.62 \mathrm{D} \\
(-0.50--11.70)\end{array}$ & $\begin{array}{c}4.92 \pm 2.47 \\
(-0.90-12.00)\end{array}$ & 0.031 \\
\hline Apikaldansitometri & $\begin{array}{c}24.20 \pm 7.74 \\
(9.50-69.20)\end{array}$ & $\begin{array}{l}33.55 \pm 15.73 \\
(17.70-100)\end{array}$ & $<0.001$ \\
\hline Km (ön yüzey) (D) & $\begin{array}{c}50.81 \pm 4.92 \\
(42.30-67.50)\end{array}$ & $\begin{array}{c}49.66 \pm 5.31 \\
(38.80-66.20)\end{array}$ & 0.031 \\
\hline$Q$ (ön yüzey) $(\mu \mathrm{m})$ & $\begin{array}{c}-0.99 \pm 1.30 \\
(-2.21-7.70)\end{array}$ & $\begin{array}{l}-0.97 \pm 0.57 \\
(-2.39-0.39)\end{array}$ & 0.900 \\
\hline Merkezi kornea kalınlığı $(\mu \mathrm{m})$ & $\begin{array}{l}453 \pm 41.25 \\
(362-547)\end{array}$ & $\begin{array}{l}430 \pm 65.92 \\
(281-669)\end{array}$ & 0.005 \\
\hline En ince kornea kalınlığı $(\mu \mathrm{m})$ & $\begin{array}{l}443 \pm 39.63 \\
(351-514)\end{array}$ & $\begin{array}{l}412 \pm 61.37 \\
(275-592)\end{array}$ & $<0.001$ \\
\hline Kmax (D) & $\begin{array}{l}59.52 \pm 7.17 \\
(48-82.40)\end{array}$ & $\begin{array}{c}58.06 \pm 7.31 \\
(47.10-80.50)\end{array}$ & 0.029 \\
\hline Kornea hacmi $\left(\mathrm{mm}^{3}\right)$ & $\begin{array}{c}57.42 \pm 2.92 \\
(51.10-63.50)\end{array}$ & $\begin{array}{c}57.59 \pm 3.55 \\
(48.90-66.70)\end{array}$ & 0.615 \\
\hline Ortalama progresyon indeksi & $\begin{array}{c}2.27 \pm 0.45 \\
(0-5.77)\end{array}$ & $\begin{array}{c}3.38 \pm 1.49 \\
(1.34-9.26)\end{array}$ & $<0.001$ \\
\hline Belin/Ambrósio ortalama değeri & $\begin{array}{c}10.33 \pm 4.11 \\
(4.71-25.43)\end{array}$ & $\begin{array}{c}11.55 \pm 4.63 \\
(3.95-29.68)\end{array}$ & 0.045 \\
\hline
\end{tabular}

Km: Ortalama keratometri değeri, Q: Asferisite değeri, KÇB: Çapraz bağlama tedavisi 
Tablo 2.Allerjikkonjonktiviti olan ve olmayan olgularda işlem sonrası dansitometri ve kornea kalınlık değişimlerinin karşılaştırılması

\begin{tabular}{lcccc}
\hline & Allerji & İşlem öncesi & Takip sonu & $\mathrm{p}$ \\
Apikaldansitometri & Var & $25.14 \pm 11.44$ & $35.33 \pm 4.35$ & 0.728 \\
& Yok & $23.63 \pm 4.35$ & $32.47 \pm 11.16$ & \\
En ince kornea & Var & $459 \pm 29.79$ & $435 \pm 59.86$ & 0.513 \\
kalınlığı $(\mu \mathrm{m})$ & Yok & $433 \pm 41.87$ & $398 \pm 58.80$ & \\
\hline
\end{tabular}

Tartışma

Keratokonus, korneanin incelmesi ve dikleşmesiyle karakterize, ilerleyici, noninflamatuar kornea ektazisidir. ${ }^{15}$ KK tedavisindeki amaç, görme keskinliğini artırmak ve hastalığın ilerlemesini durdurmaktır. Gözlük veya kontakt lensler başlangıçta tedavide yeterli olabilmekle birlikte hastalığın progresyonu üzerine etkileri bulunmamaktadır. Özellikle, pediatrik yaş grubunda başlayan KK olgularında ilerleme daha hızlı ve ilerleyen dönemlerde keratoplasti ihtiyacı, hastalık başlangıcı erişkin dönemde olanlardan daha fazladır.16,17. Reeves ve ark. KK progresyonunun 18 yaşın altındaki hastalarda daha sık ve daha hızlı olduğunu, korneal transplantasyon gereksinimi açısından yedi kat daha yüksek risk bulunduğunu tespit etmiştir. ${ }^{18}$ Gelișen tanı yöntemlerinin yaygınlaşması, özellikle bu yaş grubundaki klinik olarak semptom vermeyen vakaların erken teşhisini sağlamıştır.

KÇB tedavisinde, korneal biyomekanik gücün artırılması amaçlanmaktadır. $\mathrm{Bu}$ nedenle, etyolojiye yönelik uygulanan tek yöntemdir.KÇB çalışmaları 1990'lı yıllarda başlamış ve daha sonra tedavi insanlarda uygulanmıștır.19 Son yıllarda, KK tedavisinde yerini alan KÇB'nin, ilerlemeyi yavaşlattığı veya durdurduğu ve görme keskinliğinde artış sağladığı birçok çalışmada gösterilmiştir.20,21 Tedavi, yan etkisinin az olması ve uygulamanın kolay olması nedeniyle giderek yaygınlaşmaktadır. Ayrıca KÇB tedavisinin özellikle çocukluk çağında erişkin döneme göre daha etkili olduğunu gösteren çalışmalar da mevcuttur.22,23 Ülkemizde, 2017 yılında Subaşı ve ark. tarafından pediatrik KK vakalarında transepitelyal KÇB tedavisinin etkinliği ve güvenliğinin retrospektif olarak araştırıldığ vaka serisinde, 18 çocuk hastanın 33 gözü değerlendirilmiştir. ${ }^{24}$ Aynı çalışmada, standart epi-on KÇB prosedürü uygulanmış ve tedavinin, sonuç görme düzeylerini değiştirmediği, ancak KK progresyonunu durdurucu etki gösterdiği, keratometri değerlerindeki stabilizasyon ile gösterilmiştir. ${ }^{24}$ Benzer şekilde, bizim çalışmamızda da keratometri değerlerinde anlamlı azalma saptanmıştır. KK hastalığının ilerlemesinde karşılaştığımız kornea kalınlık değerlerinde azalma, KÇB işlemine bağlı da gelişebilmektedir. $\mathrm{Bu}$ azalma, ameliyat sonrası erken dönemlerde belirgin olsada, yaklaşık bir yıl ve sonrasında, başlangıç değerlerine yaklaşmaktadır. Erken dönemdeki incelme, keratosit apoptozu ve yeniden yapılanma ile açıklanabilirken uzun dönemdeki incelme nedeni bilinmemektedir. Bir çalışmada, ortalama 7 yll takip sonunda, KK en ince'de $15 \mu$ m'lik bir incelme saptanmıștır. ${ }^{25}$ Çalışmamızda ise, bu incelme 21 aylık takip sonunda ortalama $31 \mu \mathrm{m}$ olarak bulunmuştur. Bu durumun, hastalık progresyonu ile karıștırılmaması için diğer progresyon kriterleri ile korelasyona bakılması uygun olacaktır. Pediyatrik olgularda, hızlandırılmış KÇB’nin KK progresyonunu durdurmada en az konvansiyonel KÇB kadar etkili olduğu karşılaştırmalı bir çalışmada rapor edilmiştir. ${ }^{26}$ Benzer şekilde, bu çalışmada da takip süresi sonunda, topografik olarak ilerleme bulgusu saptanmamıştır. İnce kornealarda hipoozmolar tedavinin etkinliğinin araștırıldığı başka bir çalışmada, erken dönemde KÇB tedavisinin yan etkileri gözlenmemiştir. ${ }^{27}$ İnce kornealarda hipotonik riboflavin kullandığımız çalışmamızda, erken yada geç komplikasyon 
gözlenmemiş olup, progresyon görülmemiştir.

KÇB işlemi sonrasında enfeksiyöz keratit, korneal bulanıklık, endotel hasarı, steril infiltratlar ve herpes virüs reaktivasyonu gibi komplikasyonlar olasıdır. ${ }^{28}$ Çalışmamızda, korneal bulanıklık dışında ciddi bir komplikasyon bulgusu saptanmamıştır. Klinik anlamlı olarak ifade edilen korneal bulanıklı ise farklı çalışmalarda farklı oranlarda bildirmiştir. ${ }^{29,30}$ Çalışmamızda ameliyat sonrası gelişen korneal bulanıklık apeksteki korneal dansitometri ile takip edilmiş ve işlem öncesine göre takip süresi sonundaki dansitometri artışı istatistiksel olarak anlamlı olarak bulunmuştur. KÇB tedavisi sonrası olguların çoğunluğunda oluşan dansitometri artışı ve bulanıklığın normal bir bulgu kabul edilmesi ise tartışmalı bir konudur. ${ }^{30}$ İki olguda dansitometri artışı ileri ve subepitelyal opasite düzeyinde idi. $\mathrm{Bu}$ olgularda takip sonundaki topografik astigmatizma değeri işlem öncesine göre fazla artmış olarak ölçüldü. İstatistiksel olarak anlamlı astigmatizma artışı, bu iki olgudaki aşırı astigmatizma artışı sonucunda olabileceği düşünüldü.

Sonuç olarak, pediyatrik KK olgularında hızlandırılmış KÇB tedavisi, etkili ve güvenilir bir yöntemdir. $\mathrm{Bu}$ olgularda, daha ileri yaşlarda etkinliğin devam ettiğinin gösterilmesi için geç dönem sonuçların bildirilmesi uygun olacaktır. Aynı zamanda, hangi KÇB prosedürünün daha uzun süre ilerlemeyi durdurduğu göstermek için, karşılaştırmalı ve ileri yaş bulguları da içeren çalışmalara ihtiyaç vardır.

Çalışmanın kısıtlılıkları, retrospektif olması, kliniğimizde ön segment OCT cihazı bulunmadığı için KÇB etkinliğini değerlendirmede kullanılan korneal demarkasyon hattının değerlendirilememesi ve farklı KÇB prosedürlerinin etkinliğinin karşılaştırılamamasıdır.

\section{Kaynaklar}

1. Krachmer JH, Feder RS, Belin MW. Keratoconus and related non inflammatory corneal thinning disorders [J]. Surv Ophthalmol. 1984; 28(4): 293-322.

2. Mc Ghee CN.2008 Sir Norman Mc Alister Gregg Lecture: 150 years of practical observations on the conical cornea-what have we learned? Clin Experiment Ophthalmol 2009; 37(2): 160-76

3. Ertan A, Muftuoglu 0, Keratoconus clinical findings according to different age and gender groups. Cornea 2008; 27(10): 110913

4. Leoni-Mesplie S, Mortemousque B, Touboul D, et al. Scalability and severity of keratoconus in children. Am J.Ophthalmol 2012: 15 (4):56-62.

5. Mustafa Eliaçık, Ahmet Kırgız. İlerleyici Keratokonusta Hızlandırılmış Kollajen Çapraz Bağlama Tedavisi: 12 aylık takip sonuçları Med Res Rev 2018:1(1):15-19

6. Asri D, Touboul D, Fournié $P$, et al. Corneal collagen cross-linking in progressive keratoconus: multicenter results from the French National Reference Center for Keratoconus. J Cataract Refract Surg 2011; 37(12): 2137-43.

7. Ozgurhan EB, Kara N, Cankaya KI, et al. Accelerated corneal cross-linking in pediatric patients with keratoconus: 24month outcomes. J Refract Surg 2014;30(12):843-9.

8. Padmanabhan P, Rachapalle Reddi S, Rajagopal R, et al. Corneal Collagen Cross Linking for Keratoconus in Pediatric Patients Long Term Results. Cornea. 2017;36(1):38-43.

9. Knutsson KA, Paganoni G, Matuska S, et al. Corneal collagen cross-linking in paediatric patients affected by keratoconus. $\mathrm{Br} \mathrm{J}$ Ophthalmol. 2017; 102(2): 248-252.

10.Spoerl E, Huhle M, Seiler T. Induction of cross-links in corneal tissue [J]. Exp Eye Res. 1998;66(1):97-103.

11.Wollensak G, Spoerl E, Seiler T. Stressstrain measurements of human and porcine cornea safter riboflavin-ultraviolet-Ainduced cross-linking [J]. J Cataract Refract Surg. 2003;29(9):1780-5.

12.Caporossi A, Mazzotta C, Baiocchi S, et al. Riboflavin-UVA-induced corneal collagen 
cross-linking in pediatric patients. Cornea. 2012;31(3): 227-231.

13.Mc. Anena L, O’Keefe M. Corneal collagen crosslinking in children with keratoconus. J AAPOS. 2015;19 (3): 228-232

14. Bakshi E, Barkana Y, Goldich Y, Avni I, Zadok D. Corneal cross-linking for progressive keratoconus in children: our experience. Int J Keratoco Ectatic Corneal Dis. 2012;1(1):53-56

15. Kok YO, Tan GF, Loon SC. Review: keratoconus in Asia. Cornea 2012;31(5):581-93

16. Caporossi A, Mazotta C, Baiocchi S, Caporossi T, Denaro R. Age-related longterm functional results after riboflavin UV A corneal cross-linking. J Ophthalmol 2011;20(11):1123-7.

17. Caporossi A, Mazzotta C, Baiocchi S, Caporossi T, Denaro R, Balestrazzi A. Riboflavin-UVA-induced corneal collagen cross-linking in pediatric patients. Cornea 2012;31(3):22731.

18. Reeves SW, Stinnett S, Adelman RA, Afshari NA. Risk factors for progression to penetrating keratoplasty in patients with keratoconus. Am J Ophthalmol 2005;140 (4): 607-11

19. Dahl BJ, Spotts E, Truong JQ. Corneal collagen cross-linking: An introduction and literature review. Optometry 2012;83(1):33-42

20. Wollensak G. Cross-linking treatment of progressive keratoconus. Ophthalmology: newhope 2006;17(4):356-60.

21. Coskun seven E, Jankov MR, Hafezi F. Contralateral eye study of corneal collagen cross-linking with riboflavin and UVA irradiation in patients with keratoconus. J Refract Surg 2009;25(4):371-6.

22. Caporossi A, Mazotta C, Baiocchi S, Caporosssi T, Denaro R. Age-related longterm functional results after riboflavin UV A corneal cross-linking. J Ophthalmol 2011; 2011:608041.

23. Aslan L, Başkan A.M, Yüksel E, Aslankurt M, Özdemir M. Effect of Age Factor on Corneal Cross-linking Treatment of
Keratoconus Patients. Turk J Ophthalmol2012; 42; (6): 450-453

24. Subaşı S, Yuksel N, Balcı M.F, Demirci K, Pirhan D, Tugan B.Y, Effect of Transepithelial Cross-linking Treatment in Patients with Pediatric Keratoconus Kocaeli Medical J 2017; 6(3):36-40

25.Zotta P. G, Diakonis V. F, Kymionis G. D, Grentzelos M, Moschou K. A. Long-term outcomes of corneal cross-linking for keratoconus in pediatric patients. Journal of American Association for Pediatric Ophthalmology and Strabismus, 2017;21(5):397-401.

26.Baenninger P.B, Bachmann L.M, Wienecke L, Thiel M.A, Kaufmann C. Pediatric Corneal Cross-linking Comparison of Visual and Topographic Outcomes Between Conventional and Accelerated Treatment. Am J Ophthalmol, 2017;183(10): 11-16.

27.Gu S.F, Fan Z.S, Wang L.H, Tao X.C, Zhang Y, Wang C.Q, Mu G.Y. A short-term study of corneal collagen cross-linking with hypoosmolar riboflavin solution in keratoconic corneas. Int J Ophthalmol 2015;8(1);94.

28.Dhawan S, Rao K, Natrajan S. Complications of cornealcollagencrosslinking. Journal of ophthalmology 2011;2011:869015

29. G. Wollensak and H. Herbst, "Significance of the lacunar hydration pattern after corneal cross-linking," Cornea, 2010;29(8): 899-903.

30. C. Mazzotta, A. Balestrazzi, S. Baiocchi, C. Traversi, A. Caporossi, "Stromal haze after combined riboflavin-UVA corneal collagen cross-linking in keratoconus: in vivo confocal microscopic evaluation," Clinical and Experimental Ophthalmology 2007;35(6): 580-582. 